\title{
PEMETAAN MULTI RISIKO BENCANA PADA KAWASAN STRATEGIS DI KABUPATEN TANGGAMUS
}

\section{MAPPING OF DISASTER MULTI-RISK ASSESSMENT FOR STRATEGIC AREAS IN TANGGAMUS DISTRICT}

\author{
Dwi Abad Tiwi \\ Pusat Teknologi Reduksi Risiko Bencana, Jl. MH. Thamrin 8, Gedung II, Jakarta 10340 \\ email: dabadtiwi@gmail.com
}

\begin{abstract}
Strategic areas are prioritized development areas in order to accelerate the development of a region. Tanggamus District in The Province of Lampung has planned several strategic areas both designated by the provincial government and district government, in which will be prioritized for development with huge investment. Tanggamus District is also located in areas vulnerable to disasters include earthquakes, tsunamis, floods, and landslides. The existence of strategic areas with exposure to multiple disasters requires a multi risk assessments for disaster, so they will know the extent and location of strategic areas accompanied by multi- level disaster risk faced.
\end{abstract}

Keywords: strategic area, disaster risk, disaster multi-risk

\begin{abstract}
ABSTRAK
Kawasan strategis adalah kawasan yang diprioritaskan pembangunannya dalam rangka mempercepat pembangunan suatu wilayah. Kabupaten Tanggamus di Provinsi Lampung memiliki beberapa kawasan strategis yang direncanakan baik oleh pemerintah provinsi maupun pemerintah Kabupaten Tanggamus, yang akan diprioritaskan pembangunannya dengan investasi yang sangat besar. Kabupaten Tanggamus juga berada pada kawasan yang rentan terhadap bencana antara lain gempabumi, tsunami, banjir, dan longsor. Keberadaan kawasan strategis dengan paparan multi bencana tersebut memerlukan kajian dan pemetaan risiko multi bencana, sehingga akan diketahui luasan dan lokasi kawasan strategis disertai dengan tingkat risiko multi bencana yang dihadapi.
\end{abstract}

Kata kunci: kawasan strategis, risiko bencana, risiko multi bencana

\section{LATAR BELAKANG}

\subsection{Kawasan Strategis yang berada di Kabupaten Tanggamus}

Sesuai Rencana Tata Ruang (RTRW) Kabupaten Tanggamus Tahun 2011-2031, kawasan strategis provinsi dan kabupaten yang direncanakan berada di Kabupaten Tanggamus adalah sebagai berikut:

a. Kawasan Ekonomi Teluk Kiluan, di mana kawasan ini dikhususkan untuk kegiatan ekowisata yang terletak di Kecamatan Kelumbayan dan Kelumbayan Barat yang memang memiliki potensi ekowisata andalan. b. Kawasan pengembangan aspek lingkungan hidup yaitu Kawasan Bukit Barisan Selatan. Kawasan ini merupakan kawasan strategis skala provinsi yang berfungsi sebagai penyangga vital keseimbangan ekologi. Kawasan ini mencakup 3 desa di Kecamatan Pematang Sawa. Ketiga desa tersebut adalah Desa Tampang, Desa Tampang Muda, dan Desa Kaur Gading.

c. Kawasan Batu Balai sebagai kawasan pengembangan sumberdaya alam dan teknologi tinggi, merupakan Kawasan Industri Maritim Terpadu yang unggul dan berdaya saing tinggi. Kawasan Batu Balai terletak di Desa Ketapang, Kecamatan Limau, yang berada di kawasan pesisir. 
d. Kawasan Pengembangan Perikanan Budidaya Tangkap Minapolitan Wonosobo, yang didukung oleh sumberdaya air yang baik sehingga sangat mendukung untuk pengembangan kegiatan perikanan tangkap.

e. Kawasan Agropolitan Gisting yang terletak di Kecamatan Gisting yang berada pada ketinggian $\pm 700 \mathrm{~m}$ dpl di kaki Gunung Tanggamus, Gisting dikenal sangat sesuai untuk pertanian.

f. Kawasan Ulu Belu, untuk pengembangan aspek ekonomim yang dikembangkan sebagai kawasan Pembangkit Listrik Tenaga Gas oleh Pertamina Geothermal sebagai salah satu supplier listrik yang memenuhi kebutuhan Provinsi Lampung.

g. Kawasan pengembangan aspek lingkungan hidup Batutegi sebagai wilayah penyangga ekologis.

h. Kawasan Pulau Panggung untuk pengembangan aspek ekonomi, berupa kawasan pengembangan industri olahan hasil pertanian.

Lokasi kawasan strategis provinsi dan kabupaten di Kabupaten Tanggamus adalah seperti pada Gambar 1 berikut:

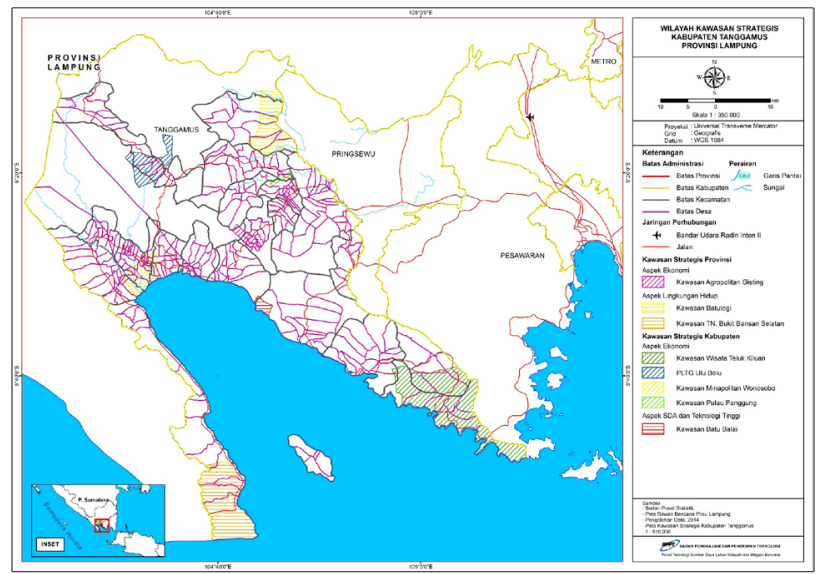

Gambar 1. Peta Kawasan Strategis Provinsi Lampung dan Kabupaten Tanggamus

(Sumber: RTRW Kabupaten Tanggamus 2011-2031)

\subsection{Kondisi Kebencanaan}

Kabupaten Tanggamus merupakan wilayah yang dilalui patahan aktif Sumatera pada segmen Semangko, kawasan ini berada pada kawasan potensi bencana risiko tinggi yaitu gempabumi dan tsunami, serta beberapa bencana seperti banjir, longsor, dan gunung api. Keberadaan berbagai potensi bencana dengan risiko tinggi ini akan mempengaruhi keberadaan berbagai kawasan strategis yang sudah direncanakan pengembangannya oleh pemerintah daerah, seperti tercantum dalam Rencana Tata Ruang Kawasan Strategis Selat Sunda (PP 26 Tahun 2008). Berbagai kawasan strategis tersebut memerlukan kehati-hatian dalam perencanaan pembangunannya, agar berbagai investasi yang sedang dan akan ditanamkan pada daerah tersebut dapat diselamatkan, dikurangi risikonya semaksimal mungkin. Salah satu upaya yang dapat dilakukan adalah dengan melakukan pemetaan multi risiko bencana pada kawasan-kawasan strategis tersebut, dan berdasarkan peta-peta tersebut dapat dilakukan perencanaan dan penataan guna lahan yang aman bencana dan seminimal mungkin risiko bencananya dapat dihindarkan. Hal ini sejalan dengan UU No.26 Tahun 2007 tentang Penataan Ruang, di mana kegiatan pada kawasan strategis merupakan berbagai kegiatan yang saling berpengaruh besar terutama untuk perlindungan investasi yang sudah cukup besar ditanamkan.

\section{METODOLOGI}

Metodologi yang dipakai untuk pemetaan risiko multi bencana pada kawasan strategis di Kabupaten Tanggamus adalah sesuai dengan Perka BNPB No.2 Tahun 2012 sebagai berikut:

2.1. Jenis ancaman bahaya yang akan dikaji meliputi: Gempabumi, Tsunami, Banjir, Longsor.

2.2. Jenis Risiko Bencana yang dihitung:

a. Fisik (rumah, jembatan, jumlah sekolah, permukiman, dII).

b. Ekonomi (lahan dan pertanian, Iahan produktif, pasar, dII).

c. Sosial Budaya (kelompok rentan: penduduk miskin, cacat, perempuan, anak-anak, dan orang tua).

2.3. Pengkajian Risiko Bencana (Perka BNPB No. 2 Tahun 2012):

a. Metoda kajian risiko bencana BNPB, dengan rumus:

Risiko = Bahaya $\mathrm{x}$ Kerentanan

b. Menggunakan 3 kelas interval risiko: rendah, sedang, tinggi.

2.4. Penyusunan Peta Multi Risiko Bencana

a. Pembuatan/ penyiapan Peta Ancaman Bencana dari lembaga yang berkompeten.

b. Penghitungan indeks jiwa terpapar dan indeks kerugian.

c. Penetapan tingkat risiko per jenis bahaya (ancaman bencana).

d. Penggabungan semuanya menjadi peta risiko multi bencana.

2.5. Penghitungan luasan Kawasan Strategis Terpapar Multi Risiko Bencana 
a. Overlay dengan Peta Kawasan Strategis Provinsi Lampung dan Kabupaten Tanggamus.

b. Penghitungan luasan kawasan strategis terpapar multi bencana.

\subsection{Sumber Data}

Peta Bahaya dari lembaga yang berkompeten (sesuai SNI), Peta land use, Citra satelit, Buku Kabupaten Dalam Angka, Podes (Potensi Desa) Kabupaten Tanggamus, Susenas, PPLS.

\section{HASIL DAN PEMBAHASAN}

\subsection{Pemetaan Risiko Bencana}

\subsubsection{Risiko Bencana Gempabumi}

Hasil pemetaan risiko bencana gempabumi untuk Kabupaten Tanggamus ditunjukkan oleh Gambar 2 berikut.

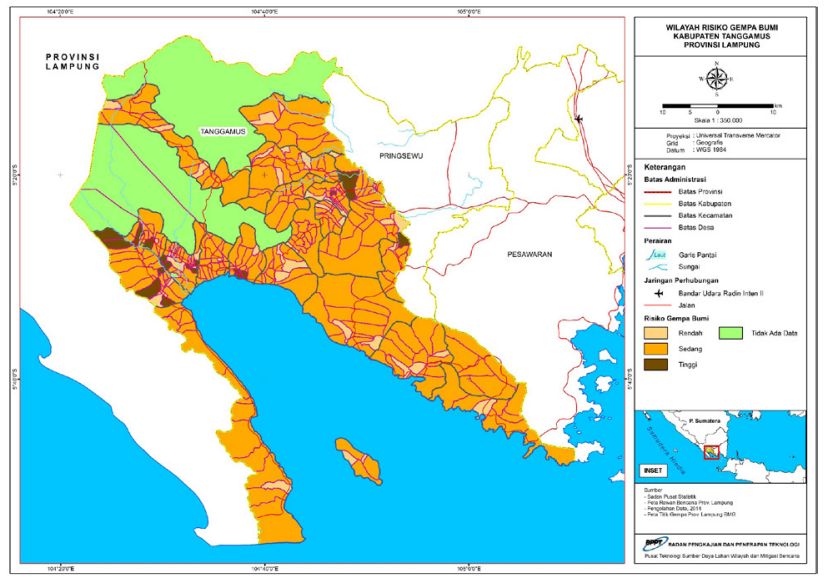

Gambar 2. Peta Risiko Bencana Gempabumi (Sumber: Hasil Analisis 20155)

\subsubsection{Risiko Bencana Tsunami}

Hasil pemetaan risiko bencana tsunami ditunjukkan oleh Gambar 3 berikut.

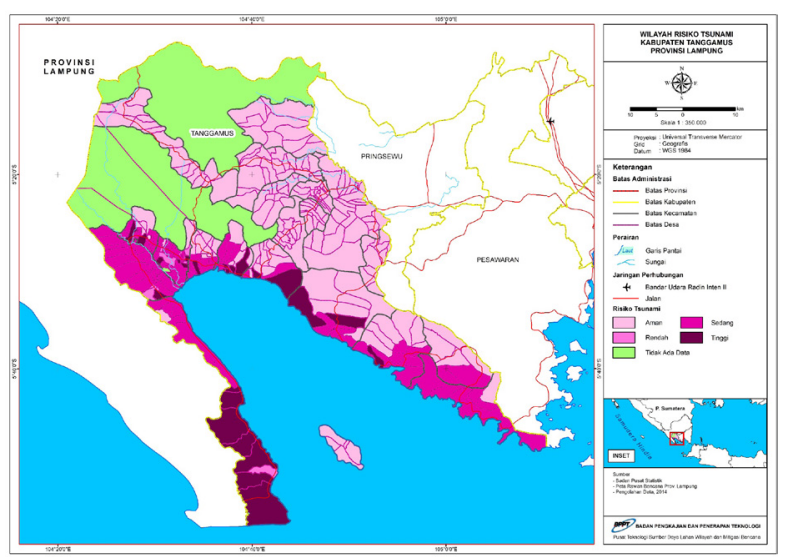

Gambar 3. Peta Risiko Bencana Tsunami

(Sumber: Hasil Analisis 2015)

\subsubsection{Risiko Bencana Banjir}

Hasil pemetaan risiko bencana banjir untuk Kabupaten Tanggamus ditunjukkan oleh Gambar 4 berikut.



Gambar 4. Peta Risiko Bencana Banjir (Sumber: Hasil Analisis 2015)

\subsubsection{Risiko Bencana Longsor}

Hasil pemetaan risiko bencana longsor Kabupaten Tanggamus ditunjukkan oleh Gambar 5 berikut.

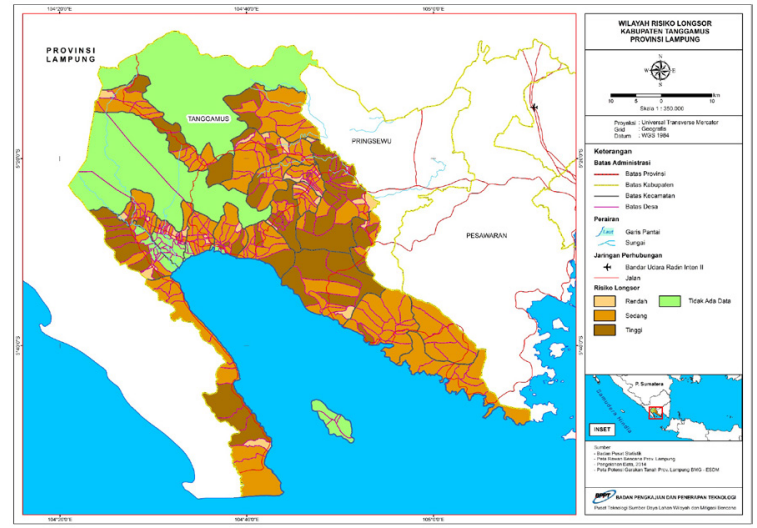

Gambar 5. Peta Risiko Bencana Longsor (Sumber: Hasil Analisis 2015)

\subsubsection{Multi Risiko Bencana}

Hasil pemetaan multi risiko bencana gempabumi, tsunami, banjir dan longsor untuk Kabupaten Tanggamus ditunjukkan oleh Gambar 6 berikut. 


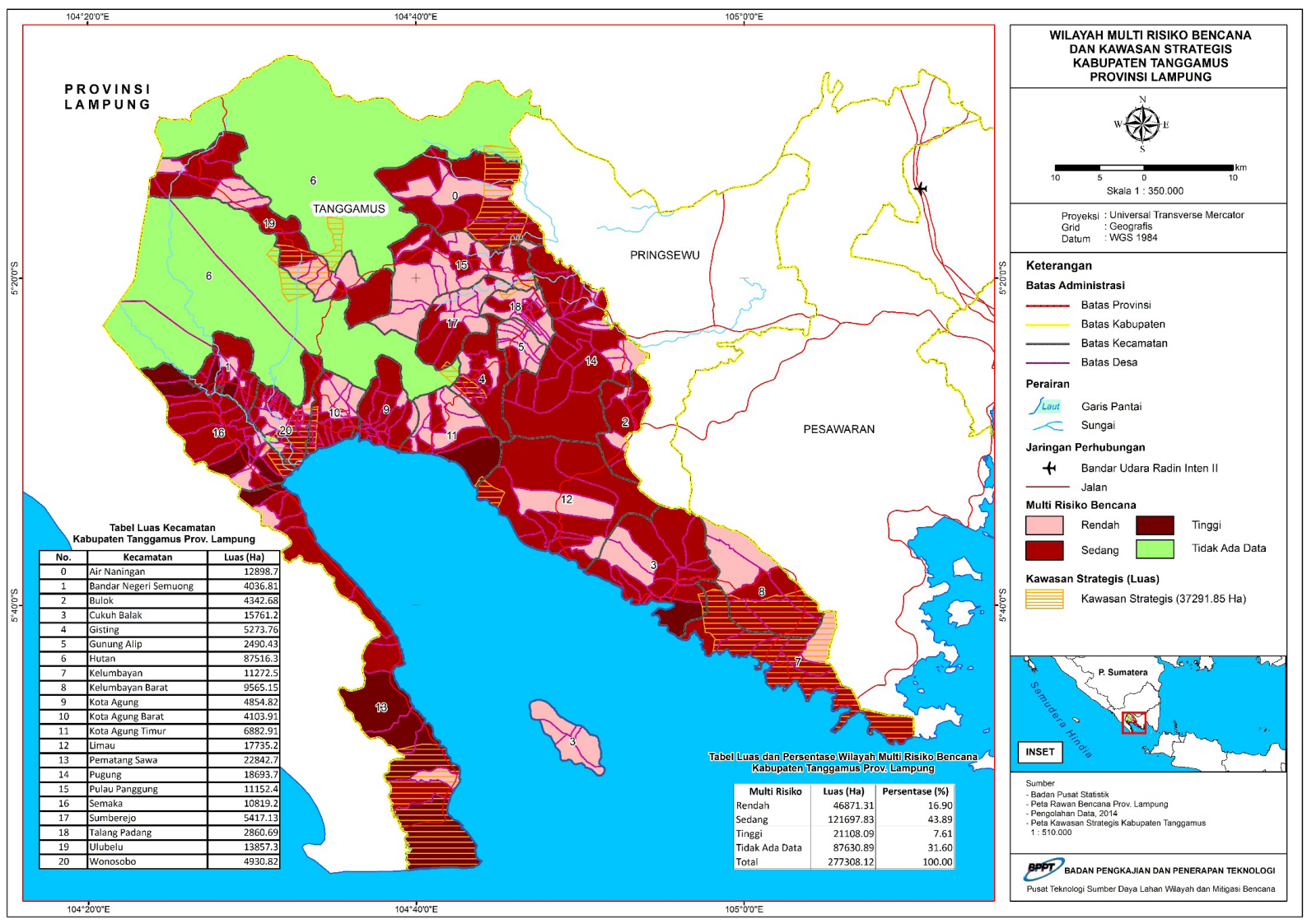

Gambar 6. Peta Multi Risiko Bencana

(Sumber: Hasil Analisis 2015)

Berdasarkan peta multi risiko bencana, secara keseluruhan, mayoritas wilayah Kabupaten Tanggamus yang merupakan wilayah dengan tingkat risiko bencana sedang adalah seluas $121.687,83$ ha atau $43,89 \%$ dari total keseluruhan. Sedangkan wilayah dengan risiko rendah dan tinggi beturut-turut $46.871,31$ ha $(16,9 \%)$ dan $21.108,09$ ha $(7,61 \%)$. Sedangkan kawasan dengan tanpa data adalah kawasan hutan lindung yang secara resmi tidak terdapat penduduk. Tabel 1 berikut menampilkan luasan wilayah Kabupaten Tanggamus dan tingkat risiko multi bencana yang dihadapi.

Tabel 1. Luasan Wilayah dan Tingkat Multi Risiko Bencana

\begin{tabular}{|c|c|c|}
\hline $\begin{array}{c}\text { Multi Risiko } \\
\text { Bencana }\end{array}$ & $\begin{array}{l}\text { Luas } \\
(\mathrm{Ha})\end{array}$ & $\begin{array}{l}\text { Persentase } \\
(\%)\end{array}$ \\
\hline Rendah & $46.871,31$ & 16,90 \\
\hline Sedang & $121.697,83$ & 43,89 \\
\hline Tinggi & $21.108,09$ & 7,61 \\
\hline Tidak Ada Data & $87.630,89$ & 31,60 \\
\hline Total & $277.308,12$ & 100,00 \\
\hline
\end{tabular}

\subsection{Multi Resiko Bencana pada Kawasan Strategis}

Berdasarkan hasil overlay Kawasan strategis di Kabupaten Tanggamus dan peta multi risiko bencana, didapatkan hasil luasan kawasan strategis dan tingkat risiko multi bencana ditunjukkan oleh Gambar 7 berikut. 


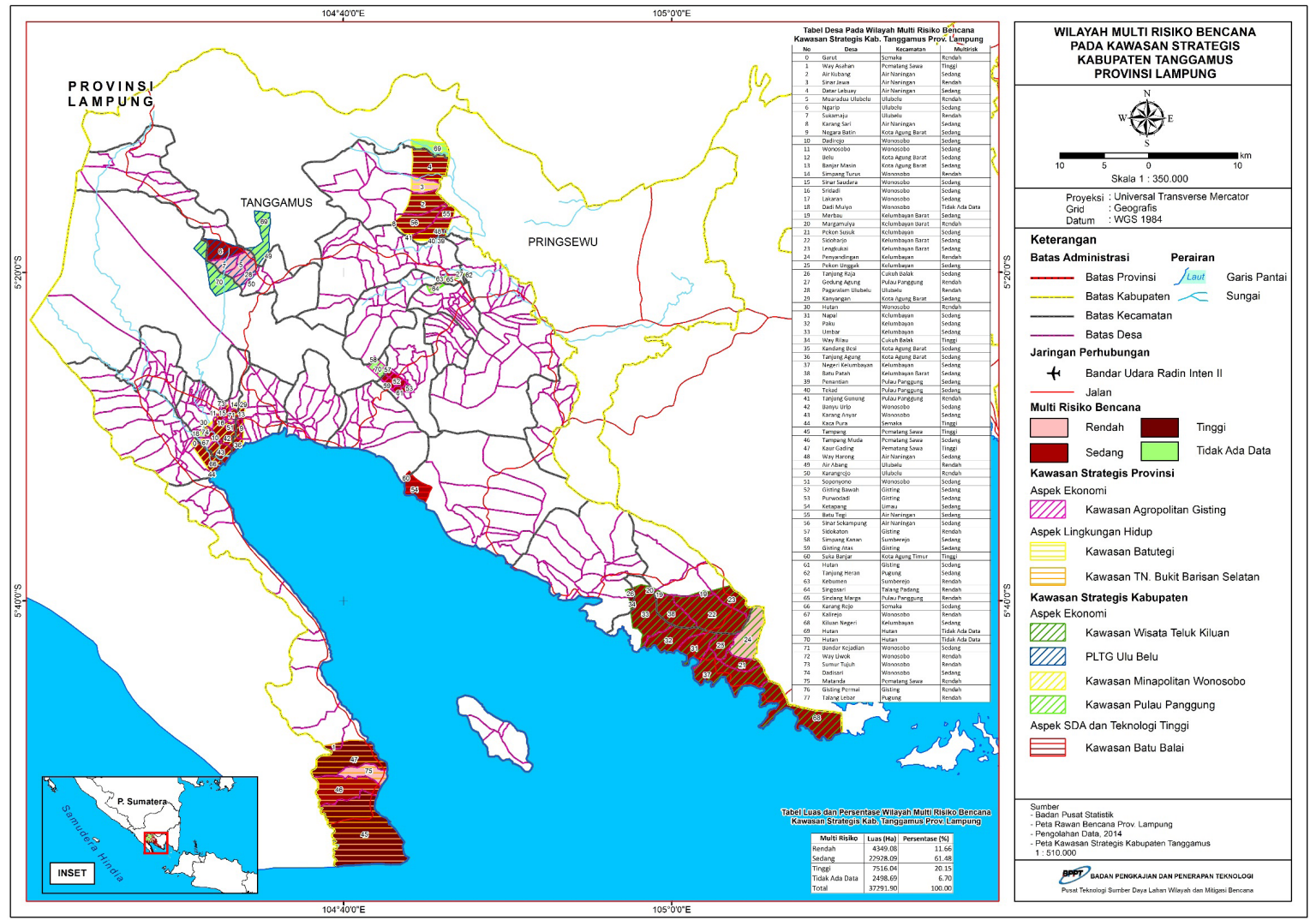

Gambar 7. Kawasan Strategis Terpapar Multi Bencana

(Sumber: Hasil Analisis 2015)

Berdasarkan hasil overlay antara Peta Kawasan Strategis di Kabupaten Tanggamus dengan peta multi risiko bencana, didapatkan informasi bahwa separuh lebih $(61,48 \%=22.928,09$ ha) luasan kawasan strategis di Kabupaten Tanggamus mempunyai tingkat risiko sedang, tingkat risiko tinggi adalah $20,15 \%(7.516,04 \mathrm{ha})$ luasan wilayah, dan tingkat risiko rendah $11,66 \%$ (4.349,08 ha) dari luasan kawasan strategis di Kabupaten Tanggamus. Tabel 2 berikut menampilkan luasan wilayah kawasan strategis di Kabupaten Tanggamus dan tingkat risiko multi bencana yang dihadapi.

Tabel 2. Luasan Kawasan Strategis dan Tingkat Multi Risiko Bencana

\begin{tabular}{|c|r|r|}
\hline $\begin{array}{c}\text { Multi Risiko } \\
\text { Bencana }\end{array}$ & \multicolumn{1}{c|}{$\begin{array}{c}\text { Luas } \\
\text { (Ha) }\end{array}$} & \multicolumn{1}{c|}{$\begin{array}{c}\text { Persentase } \\
\text { (\%) }\end{array}$} \\
\hline Rendah & $4.349,08$ & 11,66 \\
\hline Sedang & $22.928,09$ & 61,48 \\
\hline Tinggi & $7.516,04$ & 20,15 \\
\hline Tidak Ada Data & $2.498,69$ & 6,70 \\
\hline Total & $\mathbf{3 7 . 2 9 1 , 9 0}$ & $\mathbf{1 0 0 , 0 0}$ \\
\hline
\end{tabular}

Sumber: Hasil Analisis 2015

\section{KESIMPULAN DAN REKOMENDASI}

\subsection{Tingkat Risiko Kawasan Strategis Terpapar Multi Bencana}

a. Kawasan Ekonomi Teluk Kiluan: memiliki risiko bencana pada tingkat sedang. Faktor risiko penyusunnya adalah risiko banjir, longsor, gempa bumi dan tsunami yang kesemuanya dalam tingkat risiko sedang.

b. Kawasan Bukit Barisan Selatan, yang meliputi Desa Tampang, Desa Tampang Muda, dan Desa Kaur Gading, memiliki multi risiko bencana yang berbeda. Desa Tampang dan Desa Kaur Gading risiko tinggi, sedangkan Desa Tampang Muda berisiko sedang. Risiko-risiko tersebut tersusun atas risiko banjir dan gempa pada skala sedang, sedangkan longsor dan tsunami pada skala tinggi.

c. Kawasan Batu Balai yang terletak di Kecamatan Limau Desa Ketapang, yang terletak di pesisir dan bertopografi kasar ini memiliki risiko tinggi terhadap longsor dan tsunami, sedangkan dari sisi banjir dan gempa Desa Ketapang berisiko berturut-turut aman dan sedang. Atas dasar inilah Desa Ketapang termasuk ke dalam zona multi risiko tinggi. 
d. Kawasan Pengembangan Perikanan Budidaya Tangkap Minapolitan Wonosobo, memiliki risiko banjir, gempa dan tsunami pada skala sedang, sedangkan risiko longsornya rendah. Dengan demikian, secara multi risiko Wonosobo merupakan daerah dengan skala risiko sedang.

e. Kawasan Agropolitan Gisting memiliki risiko rendah terhadap banjir dan tsunami, sedang terhadap gempa dan tinggi terhadap longsor. Risiko tinggi terhadap longsor didukung oleh topografi Gisting yang bergunung.

f. Kawasan Ulu Belu, untuk pengembangan ekonomi, berada pada daerah yang cukup berisiko terhadap gempa dan longsor, meskipun pada skala sedang dan rendah. Sedangkan dari sisi risiko tsunami dan banjir, Ulubelu dinyatakan cukup aman.

g. Kawasan pengembangan aspek lingkungan hidup Batutegi. Secara risiko kebencanaan, Batutegi masuk ke dalam kelas sedang. Wilayah yang masuk ke dalam Kecamatan Air Naningan ini memiliki risiko menengah (sedang) dari sisi gempa dan longsor dan aman dari sisi banjir dan tsunami. Sebagai wilayah penyangga ekologis, Batutegi idealnya aman dari longsor.

h. Kawasan Pulau Panggung untuk pengembangan aspek ekonomi, kawasan strategis yang terletak di wilayah Kecamatan Pulau Panggang ini aman (risiko rendah) dari bencana banjir, tsunami, longsor maupun tsunami.

\subsection{Rekomendasi Tindak Lanjut}

Berdasarkan hasil kajian, dalam rangka mengurangi tingkat risiko bencana dan untuk melindungi aset investasi yang akan ditanamkan pada masing-masing kawasan strategis, maka kepada pemerintah daerah Kabupaten Tanggamus diusulkan rekomendasi tindak lanjut sebagai berikut:

a. Melakukan kajian pengurangan risiko bencana pada kawasan strategis berisiko tinggi dan sedang.

b. Melakukan penyusunan Rencana Aksi Daerah Pengurangan Risiko Bencana (RAD PRB).

c. Melakukan kajian pemilihan lokasi kawasan pengembangan Technopark Kabupaten Tanggamus.

d. Melakukan kajian unggulan komoditas untuk pengembangan kawasan strategis Agropolitan

e. Melakukan kajian kebutuhan teknologi untuk mempercepat peningkatan produksi pada masing-masing kawasan strategis.

\section{DAFTAR PUSTAKA}

BPS, Potensi Desa Kabupaten Tanggamus Tahun 2012

BNPB, 2012, Perka no 2 Tahun 2012, tentang Pedoman Umum Pengkajian Risiko Bencana

Peraturan Pemerintah No. 26 Tahun 2008 tentang Rencana Tata Ruang Kawasan Strategis Selat Sunda

RTRW Kabupaten Tanggamus Tahun 2011-2031

Undang-Undang No. 26 Tahun 2007 tentang Penataan Ruang 